\title{
O IMPACTO DO CRÔMIO NOS SISTEMAS BIOLÓGICOS
}

\author{
Alba Denise de Queiroz Ferreira*\# \\ Departamento de Química, Universidade Federal de São Carlos, CP 676, 13565-905 São Carlos - SP
}

Recebido em 17/11/00; aceito em 19/12/01

\begin{abstract}
THE IMPACT OF CHROMIUM ON BIOLOGICAL SYSTEMS. The impact of biological chromium's activity may be beneficial or not. This review presents the most relevant chemical aspects of these "two faces" of chromium by covering first, the efforts toward a clearer understanding of the carcinogenic properties of chromium compounds. The biomimetic chemistry of $\mathrm{Cr}(\mathrm{V})$ complexes illustrates the interactions of the intermediates formed by $\mathrm{Cr}(\mathrm{VI})$ reduction with DNA or oligonucleotides. The importance of trivalent chromium as an essential element is also emphasized by summarizing the recent results of the investigations on trinuclear chromium complexes as models of the cofactor responsible for the insulin activity, as well as good candidates for new nutritional supplements.
\end{abstract}

Keywords: chromium; model compounds; DNA; insulin.

\section{INTRODUÇÃO}

Crômio trivalente é reconhecido atualmente como um elemento essencial no metabolismo de carbohidratos e lipídeos, sendo que sua função está relacionada com o mecanismo de ação da insulina ${ }^{1-4}$. A quantidade recomendada de crômio a ser consumida diariamente é de 50-200 $\mu \mathrm{g}$ e a falta desse elemento na alimentação pode causar sérias complicações na saúde, como diabete e problemas cardiovasculares $^{5}$. Ao contrário do íon trivalente, no estado de oxidação VI, o crômio é classificado como composto mutagênico e carcinogênico em animais ${ }^{6}$. O dicromato e o óxido ou o ácido crômico estão entre os compostos de crômio economicamente mais importantes. Eles são utilizados na produção de tintas, como compostos de proteção de manufaturados de madeira ou couro ${ }^{7}$. No entanto, a questão da contaminação por $\mathrm{Cr}(\mathrm{VI})$ não é um problema que se restringe aos limites industriais ou aos que trabalham diretamente com os compostos, mas é também um problema ambiental (ver Figura 1), como reportado recentemente no caso das águas residuais contaminadas com crômio procedentes de curtumes em Minas Gerais ${ }^{8}$.

Esta revisão tem como objetivo apresentar os aspectos químicos mais relevantes que conduzem às atividades distintas do crômio nos sistemas biológicos. A primeira parte focalizará as interações de compostos de crômio carcinogênicos com biomoléculas, e a química biomimética dos complexos de $\mathrm{Cr}(\mathrm{IV}) / \mathrm{Cr}(\mathrm{V})$. A relevância do crômio trivalente como um elemento traço essencial será apresentada no último tópico deste trabalho. Os leitores interessados em maiores detalhes sobre a bioquímica de tais sistemas poderão consultar os trabalhos que tratam dos aspectos benéficos ${ }^{1-5} \mathrm{e}$ tóxicos do crômio ${ }^{4,6,9-11}$.

\section{A QUÍMICA AQUOSA DO CRÔMIO}

Nos sistemas fisiológicos o crômio pode ser encontrado nos estados de oxidação III-VI. Os compostos contendo $\mathrm{Cr}(\mathrm{VI}), \mathrm{Cr}(\mathrm{V})$ ou $\mathrm{Cr}(\mathrm{IV})$ são agentes oxidantes relativamente fortes em $\mathrm{pH}$ fisiológico e a estabilidade dos mesmos depende do $\mathrm{pH}$ e da concentração dos

\footnotetext{
*e-mail: alba@usp.br

\# Endereço atual: Departamento de Química, Faculdade de Filosofia, Ciências e Letras de Ribeirão Preto, Universidade de São Paulo, Av. Bandeirantes 3900, 14049-901 Ribeirão Preto - SP
}

agentes redutores. A influência da natureza dos ligantes e do $\mathrm{pH}$ sobre a estabilidade, o potencial de óxido-redução dos complexos e as características principais de cada estado de oxidação estão descritos a seguir, através de alguns exemplos.

a) $\mathrm{Cr}(\mathrm{VI}), d^{0}$ - geometria tetragonal

Em meio aquoso o íon $\mathrm{Cr}(\mathrm{VI})$ se encontra em equilíbrio:

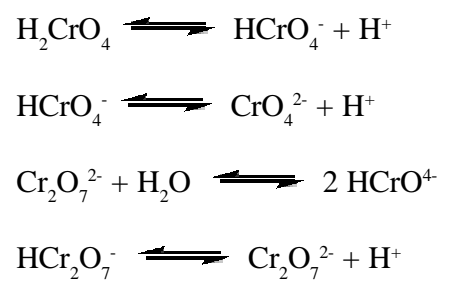

No $\mathrm{pH}$ fisiológico $(7,4)$ as formas mais importantes são $\mathrm{CrO}_{4}^{2-}$ (76 \%) e $\mathrm{HCr}_{2} \mathrm{O}_{7}^{-}(24 \%)$. O processo de redução depende do $\mathrm{pH}$ como descrito nas Eq. 5-6:

$\mathrm{Cr}_{2} \mathrm{O}_{7}^{2-}+14 \mathrm{H}^{+}+6 \mathrm{e}^{-} \rightarrow 2 \mathrm{Cr}^{3+}+7 \mathrm{H}_{2} \mathrm{O} \mathrm{E}_{0}=1.33 \mathrm{~V}$
$\mathrm{CrO}_{4}^{2-}+4 \mathrm{H}_{2} \mathrm{O}+3 \mathrm{e}^{-} \rightarrow \mathrm{Cr}(\mathrm{OH})_{3}+5 \mathrm{OH}^{-} \mathrm{E}_{0}=-0.12 \mathrm{~V}$

b) $\mathrm{Cr}(\mathrm{V}), d^{I}$ - geometria piramidal de base quadrada

A concentração do íon $\mathrm{Cr}(\mathrm{V})$ em solução é determinada de modo geral através da espectroscopia de RPE, mas outras técnicas, incluindo EAX, tem sido utilizadas para a caracterização de complexos de $\mathrm{Cr}(\mathrm{V})^{12}$. O crômio se apresenta neste estado de oxidação como intermediário da reação de redução do $\mathrm{Cr}(\mathrm{VI})$ com redutores orgânicos. Também já foi demonstrado que é possível isolar e caracterizar, através da determinação de estruturas cristalográficas, complexos de $\mathrm{Cr}(\mathrm{V})$ relativamente estáveis ${ }^{13}$, sendo que duas dessas estruturas são apresentadas na Figura $2^{14}$. Esses complexos com estrutura definida tem sido utilizados como modelos nos estudos da reatividade do $\mathrm{Cr}(\mathrm{V})$ e são geralmente estabilizados por ligantes que contém um grupo diol, em especial os derivados 1,2-dihidróxido ${ }^{15}$. A estabilidade cinética de tais complexos depende não somente da estrutura do ligante, mas prin- 


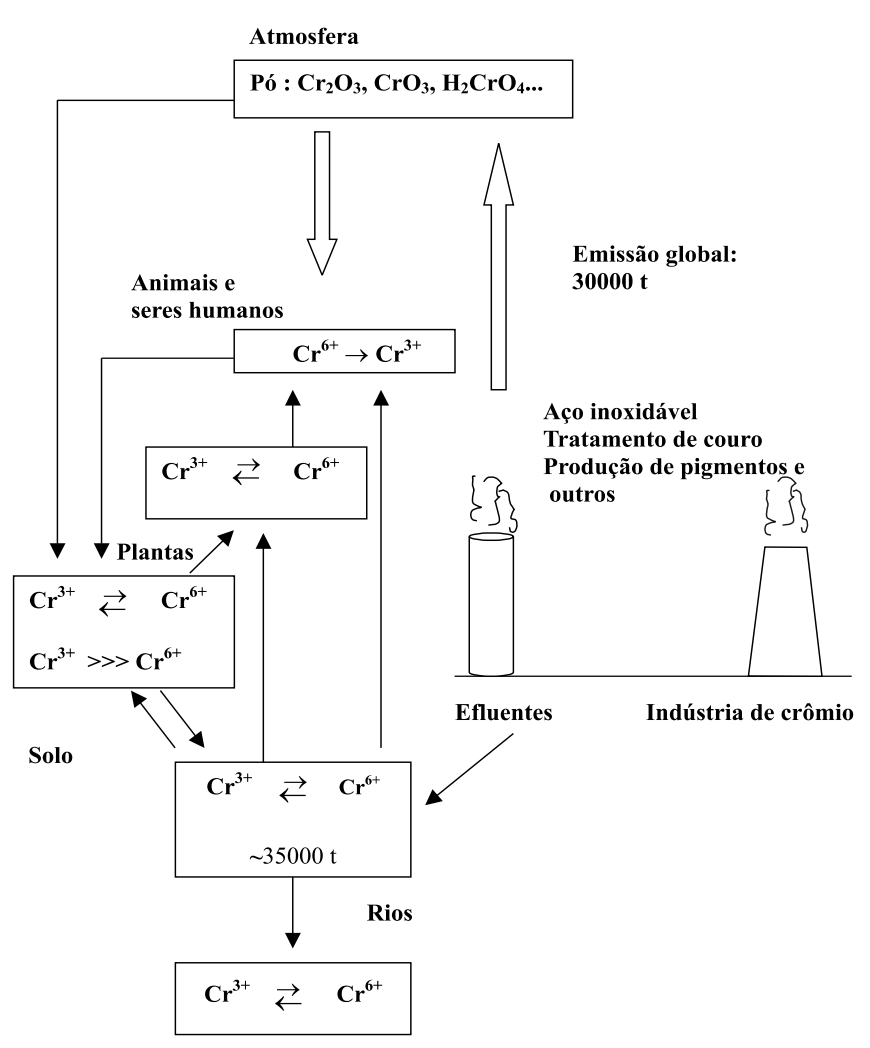

Mares e oceanos

Figura 1. Representação esquemática dos problemas ambientais causados pelo crômio (adaptado da referência 10)

cipalmente da capacidade redutora do mesmo. Por exemplo, ligantes com potencial de redução mais altos como o-aminofenol, 8hydroxyquinolina, tolueno-3,4-ditiol, ácido tioglicólico ou ascórbico, reduzem rapidamente $\mathrm{Cr}(\mathrm{V})$ a $\mathrm{Cr}(\mathrm{III})^{13}$. Nas faixas de $\mathrm{pH}$ elevado, $\left[\mathrm{Cr}(\text { ehba })_{2} \mathrm{O}^{1-}\right.$ (1) desproporciona-se em $2 \mathrm{Cr}(\mathrm{VI}), \mathrm{Cr}(\mathrm{III})$ e em pH ácido o ligante se oxida gradualmente ${ }^{16}$. Um recente e detalhado estudo cinético de desproporcionamento do complexo 1 na faixa de $\mathrm{pH}$ $6,0-8,0\left(\mathrm{NaClO}_{4}=1,0 \mathrm{M}, 37^{\circ} \mathrm{C}\right)$, indicou que a reação $3 \mathrm{Cr}(\mathrm{V}) \rightarrow 2$ $\mathrm{Cr}(\mathrm{VI})+\mathrm{Cr}(\mathrm{III})$ é acelerada por íons fosfatos ${ }^{17}$. Alguns complexos de $\mathrm{Cr}(\mathrm{V})$ são estáveis por várias horas dependendo do $\mathrm{pH}$, por exemplo: complexo 1, em pH ácido; [Cr(hmhea) $\left.\left(\mathrm{CH}_{3} \mathrm{OH}\right)\right]$ (2), em pH fisiológi$\mathrm{Co}^{12} ;\left[\mathrm{CrO}_{4}\right]^{3-}(3)$, em $\mathrm{pH}$ básico ${ }^{13}$.

Buscando uma melhor compreensão sobre a formação dos complexos de $\mathrm{Cr}(\mathrm{V})$, intermediários da redução intracelular do $\mathrm{Cr}(\mathrm{VI})$, foram estudadas as reações de substituição, o mecanismo e a cinética das reações redox envolvendo $\mathrm{Cr}(\mathrm{V})^{18,19}$. No caso da reação de substituição, foram utilizados complexos de $\mathrm{Cr}(\mathrm{V})$ contendo o ácido quínico, o qual possui um grupo ácido terc-2-hidróxido e dois grupos diois, cis-(O3,O4) e trans $(\mathrm{O} 4, \mathrm{O} 5)$. Esta disposição dos grupos funcionais 1,2 diol e do ácido 2-hidróxido possibilitou o estudo da competição intramolecular na coordenação do ácido quínico com o crômio em função do $\mathrm{pH}^{19}$. Os estudos de RPE forneceram indicações referentes a geometria dos complexos e sobre os isômeros de ligação que foram formados ao longo da reação. Os resultados indicaram que os grupos ácidos 2-hidróxi estabilizam melhor o íon $\mathrm{Cr}(\mathrm{V})$ se comparados com os grupos 1,2-dióis em valores de $\mathrm{pH}<4,0$; no entanto, verificou-se que o efeito de estabilização é inverso quando cromatos solúveis são absorvidos para o interior da célula em $\mathrm{pH}=7,4$.
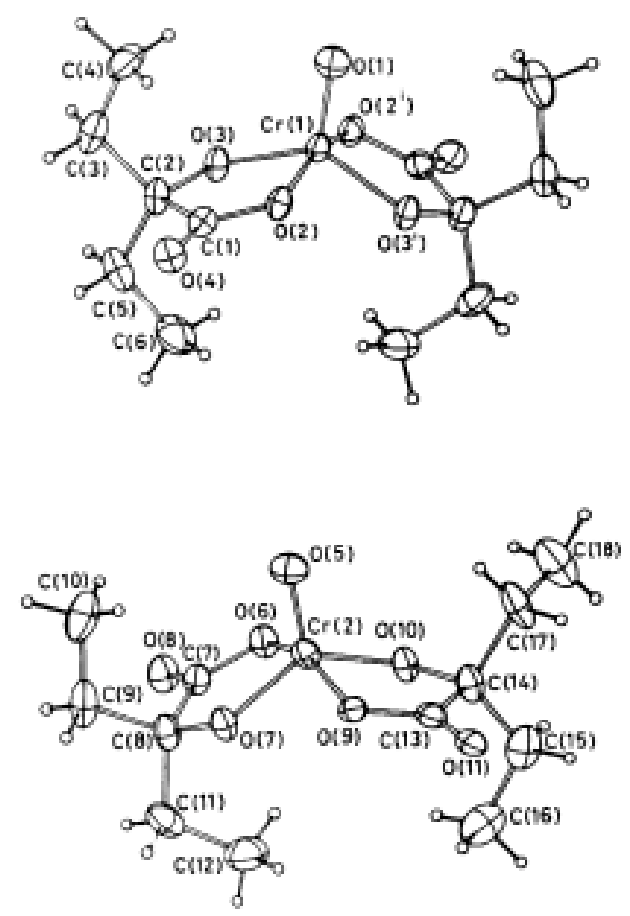

Figura 2. Estrutura de dois ânions independentes no complexo $\mathrm{Na}\left[\mathrm{Cr}(\text { ehba })_{2} \mathrm{O}\right] \cdot 1,5 \mathrm{H}_{2} \mathrm{O}$ (adaptado da referência 14)

c) $\mathrm{Cr}(\mathrm{IV}), d^{2}$ - geometria octaédrica ou piramidal de base quadrada.

Atualmente a química aquosa do Cr(IV) tem sido alvo de estudos que se concentram nas reações redox e de troca de ligantes ${ }^{20}$. Em solução aquosa, o tempo de vida desses complexos é muito curto e assim as estruturas representadas na Figura 3 foram sugeridas com base nos resultados de técnicas espectroscópicas como UV/Vis e $\mathrm{DC}^{20,21}$. Em faixas de $\mathrm{pH}$ elevado, complexos de $\mathrm{Cr}(\mathrm{IV})$ desproporcionam-se em $\mathrm{Cr}(\mathrm{V})$ e $\mathrm{Cr}(\mathrm{III})^{20}$.

\section{d) $\mathrm{Cr}(\mathrm{III}), d^{3}$ - geometria octaédrica}

Devido à inércia cinética dos íons na configuração $d^{3}$, as reações de troca de ligantes nos complexos de $\mathrm{Cr}$ (III) são muito lentas. Por exemplo, no caso do $\left[\mathrm{Cr}\left(\mathrm{H}_{2} \mathrm{O}\right)_{6}\right]^{3+}$ a constante de velocidade de troca de $\mathrm{H}_{2} \mathrm{O}$ é $\mathrm{k}=4.510^{-7} \mathrm{~s}^{-1}$ na temperatura ambiente. Como demostrado na Eq. 7, o íon hexaaqua é ácido, podendo formar dímeros do tipo $\left[\left(\mathrm{H}_{2} \mathrm{O}\right)_{4} \mathrm{Cr}(\mu-\mathrm{OH})_{2} \mathrm{Cr}\left(\mathrm{OH}_{2}\right)_{4}\right]^{4+}$. Com adição gradual de base, ocorre polimerização até a formação de complexos de alta nuclearidade ${ }^{22}$.

Outro aspecto importante é o fato de que na presença de acetatos ou de seus derivados, ocorre facilmente a formação de complexos trinucleares $\left[\mathrm{Cr}_{3} \mathrm{O}\left(\mathrm{O}_{2} \mathrm{CR}\right)_{6}\left(\mathrm{H}_{2} \mathrm{O}\right)_{3}\right]^{+}$, conhecidos como de tipo"básico" 23,24 . A coordenação do óxido $\mu_{3}$ central é do tipo triângulo planar com os íons crômio do complexo. Cada par de íons crômio é ligado por dois carboxilatos e a coordenação do íon metálico é

$$
\left[\mathrm{Cr}\left(\mathrm{OH}_{2}\right)_{6}\right]^{3+} \underset{\substack{+\mathrm{H}^{+} \\ \mathrm{pKa}=4}}{\stackrel{-\mathrm{H}^{+}}{\rightleftharpoons}}\left[\mathrm{Cr}\left(\mathrm{OH}_{2}\right)_{5}(\mathrm{OH})\right]^{2+} \rightleftharpoons\left[\left(\mathrm{H}_{2} \mathrm{O}\right)_{4} \mathrm{Cr}(\mu-\mathrm{OH})_{2} \mathrm{Cr}(\mathrm{OH})_{4}\right]_{2}^{4+}
$$




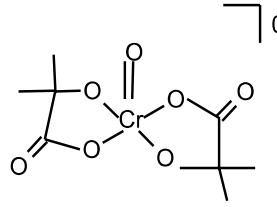

[Cr(ehba) $\left.)_{2} \mathrm{O}\right](3)$

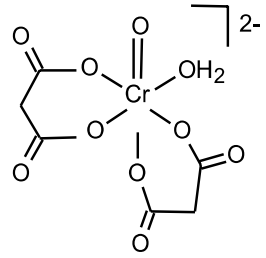

$\left[\mathrm{Cr}(\mathrm{mal})_{2} \mathrm{O}\right]^{2-}(4)$

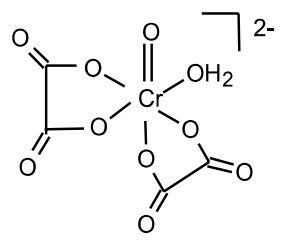

[Cr(oxal) $2 \mathrm{O}](5)$<smiles></smiles>

[Cr(pic) $\left.{ }_{2} \mathrm{O}\right](6)$

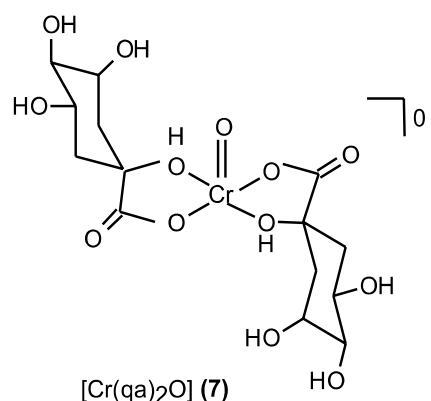

Figura 3. Possíveis estruturas de novos complexos de Cr(IV) determinadas em solução (adaptado da referência 20)

preenchida por uma molécula $\mathrm{H}_{2} \mathrm{O}$ terminal (ver Figura 4). Essa estrutura confere características físicas e químicas particulares a esses compostos trinucleares ${ }^{23}$. Tais complexos de $\mathrm{Cr}(\mathrm{III})$, em contraste

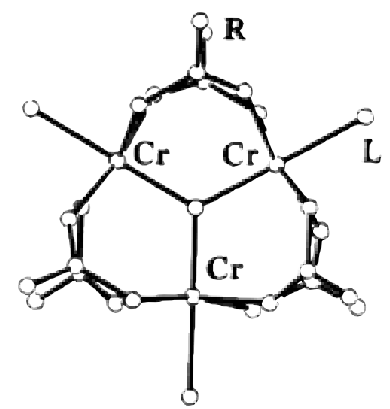

Figura 4. Estrutura dos cátions trinucleares carboxilatos de crômio oxocentrados: composto 8, $\mathrm{L}=\mathrm{H}_{2} \mathrm{O}, \mathrm{R}=\mathrm{CH}_{3}$; composto 9, $\mathrm{L}=\mathrm{H}_{2} \mathrm{O}, \mathrm{R}=$ $\mathrm{CH}_{2} \mathrm{CH}_{3}$ com os isoestruturais contendo $\mathrm{Mn}(\mathrm{III})$ ou $\mathrm{Fe}(\mathrm{III})$, são estáveis em solução aquosa e são recristalizados a partir de solução de ácido mineral diluído. Apesar da presença do centro metálico $d^{3}$, os complexos de crômio do tipo "básico" podem também ser caracterizados em solução através das técnicas paramagnéticas de RMN ${ }^{24}$.

\section{O PROCESSO DE REDUÇÃO DO ÍON Cr(VI) E AS SUAS CONSEQÜÊNCIAS}

À luz dos fatos citados anteriormente, o enfoque das pesquisas tem sido principalmente sobre as interações dos compostos de crômio com substratos biológicos, embora o mecanismo do processo carcinogênico seja ainda alvo de discussões ${ }^{9-11,18,25}$. Uma das propostas de mecanismo, o de clivagem oxidativa do ADN, ilustrada na Figura 5, aponta para três fatos importantes ${ }^{18}: 1$ ) a coordenação do grupo fosfato com o crômio pentavalente é uma etapa fundamental; 2) a formação do complexo intermediário $\mathrm{Cr}(\mathrm{V})$-diesterfosfato induz a clivagem da molécula de $\mathrm{ADN}$; 3 ) o complexo $\mathrm{Cr}$ (III)-grupo

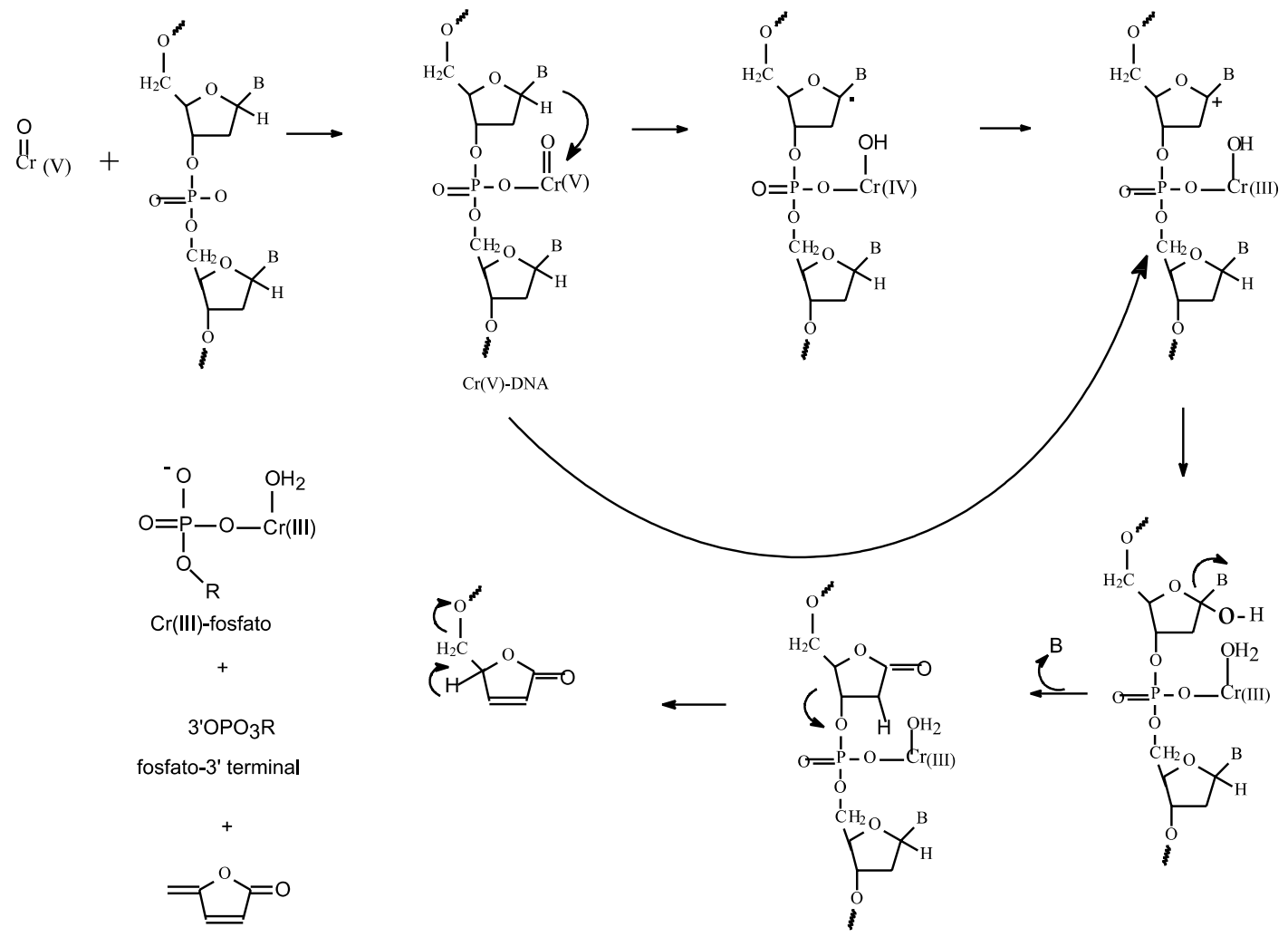

Figura 5. Sugestão de mecanismo da clivagem oxidativa do DNA induzida por íons de Cr(V) (adaptado da referência 18) 
fosfato é o produto final desta reação. Neste estudo, partindo-se dos complexos 1 e [Cr(V)-BT] $]^{2-}$, sugere-se que os produtos das reações de óxido-redução resultam da abstração de um átomo de $\mathrm{H}$ do carbono C1'(ver Figura 5). Em contraste, nos experimentos biomiméticos da clivagem oxidativa de oligonucleotídeos e da molécula de ADN, na presença ou ausência de $\mathrm{H}_{2} \mathrm{O}_{2}$, demonstrou-se que a reação de oxidação inicia-se quando um átomo de $\mathrm{H}$ é removido do $\mathrm{C} 4$ ', ocasionando clivagens dependente e independente do $\mathrm{O}_{2}^{25}$.

Crômio hexavalente por si mesmo não é capaz de coordenar-se aos ligantes disponíveis no meio celular, enquanto que os produtos das reações redox dos compostos de $\mathrm{Cr}$ (VI) formam compostos com tais ligantes, danificando assim as funções da célula. Durante estas reações de oxido-redução são obtidos complexos intermediários de $\mathrm{Cr}(\mathrm{V})$ e $\mathrm{Cr}(\mathrm{IV})$. Estudos que abordam os aspectos mecanísticos da reação, sugerem que no final da redução há formação de radicais e uma mistura de complexos de $\mathrm{Cr}$ (III) contendo derivados de ligantes que, após sofrerem redução, se encontram no interior da célula ${ }^{9-11,26}$. Com a finalidade de esclarecer os processos de absorção do íon crômio hexavalente dentro da célula e a subsequente redução, Connet e Wetterhahn sugeriram o modelo "absorção-redução" ${ }^{27}$ representado na Figura 6. No pH fisiológico, o $\mathrm{Cr}(\mathrm{VI})$ se encontra nas formas $\mathrm{HCrO}_{4}^{-}$e $\mathrm{CrO}_{4}^{2-}$, as quais se assemelham estruturalmente aos íons $\mathrm{SO}_{4}^{2-}$ e $\mathrm{HPO}_{4}^{2-}$, e por isso são absorvidas para dentro da célula através dos canais iônicos ${ }^{28}$. Por outro lado, a absorção de complexos de $\mathrm{Cr}$ (III) é muito mais lenta; no entanto, o potencial mutagênico de alguns complexos não pode ser desconsiderado. Por exemplo, investigações recentes apresentaram evidências da ação mutagênica dos complexos cis- $\left[\mathrm{Cr}(\text { phen })_{2}\left(\mathrm{H}_{2} \mathrm{O}\right)_{2}\right]^{3+}$ e trans- $\left[\mathrm{Cr}(\text { salen })\left(\mathrm{H}_{2} \mathrm{O}\right)_{2}\right]^{2+}$, relacionando a permeabilidade intracelular e a toxidez com a facilidade com que tais complexos são oxidados a $\mathrm{Cr}(\mathrm{V})^{29}$.

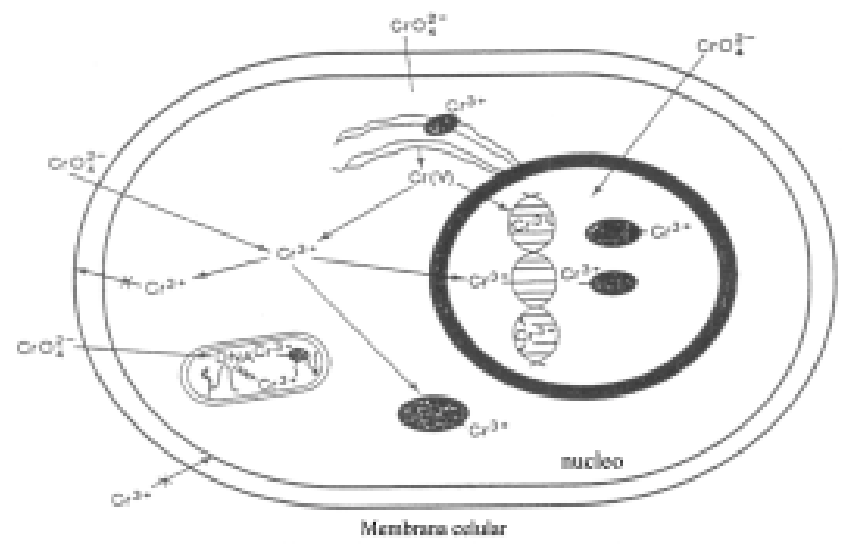

Figura 6. Modelo “absorção-redução" (adaptado da referência 27)

No meio celular existem vários redutores que podem participar do processo de redução do $\mathrm{Cr}(\mathrm{VI})$ como glutationa, ascorbato, cisteína, íon peróxido, flavoenzimas e açúcares. É necessário salientar a capacidade dos açúcares em reduzir compostos de $\mathrm{Cr}(\mathrm{VI})$, sendo que vários complexos de $\mathrm{Cr}$ (III)-carbohidratos já foram isolados; contudo, as estruturas cristalográficas dos mesmos ainda estão por ser determinadas ${ }^{30,31}$.

Em condições fisiológicas, as concentrações dos redutores são maiores que a do crômio. Por exemplo, em um experimento encontrou-se que a concentração do crômio nos rins de rato era $0,55 \mathrm{mM}$, após $2 \mathrm{~h}$ da injeção de uma solução $10 \mathrm{mg} / \mathrm{kg} \mathrm{Na}_{2} \mathrm{CrO}_{4}{ }^{32}$. A concentração de ascorbato in vivo nos rins ou fígado de rato foi estimada em $1 \mathrm{mM}{ }^{33}$, sendo que a concentração de glutationa, o peptídeo com o grupo SH mais abundante no interior da célula de mamíferos, é de aproximadamente $8 \mathrm{mM}{ }^{27}$. Em outro experimento determinou-se que a maior parte do crômio (70 \%) se encontra no citoplasma, 29,4\% está na região do núcleo e somente $0,56-1,6 \%$ se concentra no $\mathrm{ADN}^{34}$. É importante ressaltar as concentrações dos grupos fosfatos nas células. Estima-se que a concentração dos grupos fosfatos do ADN nas células eucarióticas é de $5-10 \mathrm{mM}^{35}$, sendo que no ATP é de 1-5 $\mathrm{mM}^{36}$

Recentemente, um estudo envolvendo a produção de um complexo macrocíclico de $\mathrm{Cr}(\mathrm{V})$ através de redutores inorgânicos ou orgânicos e a subseqüente reação deste complexo com o ADN, sugere que a extensão e a natureza da lesão dependem dos redutores que formam as diferentes espécies capazes de danificar o $\mathrm{ADN}^{37}$. A análise dos tipos de danos causados à molécula do ADN pela redução do cromato na presença de cisteína, indicou a presença de interações iônicas e a formação de complexos Cr-ADN com bom rendimento ${ }^{38}$. Neste caso, foi observada a ausência completa de qualquer tipo de clivagem do ADN, mesmo utilizando-se várias concentrações de $\mathrm{Cr}(\mathrm{VI})$, sugerindo que os complexos de $\mathrm{Cr}(\mathrm{V})$ e $\mathrm{Cr}(\mathrm{IV})$ produzidos durante a redução do cromato por cisteína possuem reatividade diferente da dos complexos modelos sintéticos mencionados anteriormente.

\section{INTERAÇÕES DOS ÍONS Cr(III), Cr(IV) E Cr(V) COM PROTEÍNAS E COM O ADN.}

Dentre as proteínas que interagem com íon de crômio trivalente, encontram-se aquelas que estão envolvidas no processo de redução: NADPH-citocromo P-450 redutase, citocromo P-450, diaforase, hemoglobina ${ }^{39}$. No sistema fisiológico humano, o crômio chega até os tecidos através da transferrina, a mesma proteína envolvida no transporte de ferro ${ }^{40}$. Convém enfatizar que segundo os nossos conhecimentos, ainda não foi resolvida nenhuma estrutura cristalográfica dos sistemas acima.

Um outro interesse no estudo das interações Cr(III)-biomoléculas está relacionado com o uso das propriedades químicas, magnéticas e espectroscópicas de complexos de Cr(III) na obtenção de sondas inorgânicas, para auxiliar a determinação dos tipos de ligação de moléculas pequenas na superfície de proteínas e do ADN. Tem-se como exemplo, a utilização das propriedades magnéticas do $\mathrm{Cr}$ (III) nos estudos sobre a ligação de complexos de crômio com proteínas, através do método da extinção do efeito NOE e do alargamento dos sinais de $\mathrm{RMN}^{41}$. Além desses exemplos, tem-se os experimentos envolvendo a espectroscopia de luminescência associada com a eletroforese capilar, que forneceram informações pertinentes sobre a natureza e a estereoseletividade enantiomérica das interações de complexos do tipo $\mathrm{Cr}$ (diimina) ${ }_{3}$, com polinucleotídeos e o $\mathrm{ADN}^{42}$.

No contexto da toxidez do crômio, vários esforços tem sido realizados por químicos, farmacólogos e bioquímicos para identificar os danos que o processo de redução do $\mathrm{Cr}(\mathrm{VI})$ pode causar ao $\mathrm{ADN}$, os quais podem ser divididos em 4 grupos: formação de adutos $\mathrm{Cr}$ $\mathrm{ADN}^{38,43}$, ligações $\mathrm{Cr}$-ADN-proteínas de diferentes formas ${ }^{44}$, clivagem do $\mathrm{ADN}^{45}$ e oxidação do $\mathrm{ADN}^{46-48}$

Pesquisas mais recentes sugerem que o íon $\mathrm{Cr}(\mathrm{V})$, formado durante o processo de redução, é a forma mais reativa do crômio com a capacidade de formar os adutos Cr-ADN, uma vez que neste estado de oxidação a configuração $d^{l}$ é mais lábil que a $d^{3}$ do $\operatorname{Cr}(\mathrm{III}){ }^{12,19,49}$. Com respeito a reatividade dos complexos de $\mathrm{Cr}(\mathrm{V})$ com o ADN e com os seus componentes, observou-se que a coordenação do $\mathrm{Cr}(\mathrm{V})$ com os grupos organofosfatos é uma etapa fundamental na reação de oxidação dos nucleotídeos ${ }^{50}$ e na clivagem oxidativa do ADN. Os resultados da investigação da capacidade do complexo 1 em clivar a molécula do ADN, realizados nas condições de $\mathrm{pH}=6.0-8.0$, 
$\left[\mathrm{NaClO}_{4}\right]=1.0 \mathrm{M}, 37^{\circ} \mathrm{C}$, e os experimentos cinéticos estudados em condições similares ${ }^{17}$, mostraram que a interação direta com os grupos fosfatos é provavelmente a primeira etapa no mecanismo de clivagem do ADN em solução aquosa e pH neutro. Posteriormente, experimentos realizados com complexos de $\mathrm{Cr}(\mathrm{IV})$ e ácido quínico, demonstraram que os mesmos são capazes de quebrar a molécula de ADN na presença de excesso do ácido na faixa de pH 3,5-6,0 a 37 ${ }^{\circ} \mathrm{C}^{51}$. Tal resultado representa a primeira evidência direta de que complexos de $\mathrm{Cr}(\mathrm{IV})$ podem também induzir a clivagem do ADN.

Complementando a participação dos compostos intermediários acima e a formação dos adutos Cr-ADN, é necessário enfatizar a importância considerável dos íons $\mathrm{Cr}$ (III) neste processo. Experimentos de EAX com células de hamster chinês $V 79$ que foram expostos a $\mathrm{Cr}(\mathrm{VI})$ e $\mathrm{Cr}(\mathrm{V})$, indicaram que após 4 horas, $90 \%$ do crômio foi reduzido a $\mathrm{Cr}(\mathrm{III})^{52}$. Testes in vitro realizados para investigar a influência do crômio trivalente sobre a duplicação do ADN mostraram que este íon metálico pode ser um fator importante na mutagênese induzida por cromato $^{53,54}$. Outros pesquisadores comprovaram que em concentrações elevadas ([Cr] > $10 \mu \mathrm{M})$, o íon $\mathrm{Cr}$ (III) é capaz de bloquear a síntese do $\mathrm{ADN}^{55}$. Isto indica que apesar da inércia cinética dos complexos de $\mathrm{Cr}$ (III), eles são capazes de formar ligações covalentes com grupos funcionais de proteínas e ácidos nucléicos.

Um ponto que permaneceu em discussão durante muitos anos, foi o sítio ao qual o crômio se coordena na molécula do ADN. As primeiras investigações sugeriram o N7 da guanina, pois nos experimentos com polinucleotídeos, a maior porcentagem do íon metálico se concentrava no polinucleotídeo rico em guanina, poli $(\mathrm{G})^{56}$. No entanto, depois de retomada a questão, ficou estabelecido que não se trata de uma especificidade à base guanina, mas sim aos grupos fosfatos ${ }^{57}$. Este resultado condiz com os princípios de Pearson com respeito ao caráter de ácido duro do íon $\mathrm{Cr}(\mathrm{III})^{58,59}$.

Considerando a ausência completa de dados estruturais sobre a interação $\mathrm{Cr}$ (III)-ADN a fim de comprovar tais fatos, a preparação de compostos modelos constituiu-se na primeira etapa para a obtenção de maiores informações sobre a natureza desta interação. Os ligantes difenil fosfato e monofenil fosfato foram escolhidos como representantes de uma unidade básica dos grupos fosfoéteres do $\mathrm{ADN}^{60,61}$.

Um outro aspecto da interação $\mathrm{Cr}$ (III)-fosfato foi apresentado, com as evidências da fosforilação da proteína albumina de soro bovino promovida pelo complexo $\left[\mathrm{Cr}\left(\mathrm{NH}_{3}\right)_{5}(\mathrm{OH})\right]^{2+62}$. Os autores propõem que esse tipo de reação tem implicações no processo de intoxicação por íons crômio. Por outro lado, como será enfatizado no próximo tópico, vários experimentos apontam para as reações de fosforilação/defosforilação como etapas fundamentais da atividade nutricional dos complexos de $\mathrm{Cr}$ (III).

\section{A RELEVÂNCIA BIOLÓGICA DO CRÔMIO TRIVALENTE}

A forma biologicamente ativa e de ocorrência natural do crômio é um oligopeptídeo constituído por glicina, cisteína, aspartato, glutamato e contém quatro íons de crômio ${ }^{63}$. Como sua estrutura molecular ainda não foi determinada, é conhecido genericamente como 'substância de mais baixo peso molecular ligada ao crômio', "lower molecular weight binding chromium substance"- $\mathrm{LMWCr}^{64-}$ ${ }^{66}$. Devido a inércia do crômio, é muito pouco provável que esse íon esteja envolvido em algum processo enzimático; mesmo assim, a função do LMWCr na ativação de reações de fosforilação e defosforilação tem sido investigadas ${ }^{67}$.

A fosforilação de proteínas é catalisada por uma grande classe de enzimas conhecidas como proteínas-cinases. A atividade dessas enzimas é afetada, principalmente, pela natureza e concentração de íons metálicos divalentes. A proteína-cinase capaz de fosforilar tirosina é denominada tirosina cinase; a reação de fosforilação está representada na Eq. 8. As proteínas-cinases utilizam um nucleotídeo trifosfato, geralmente ATP, para a transferência do grupo fosforila ao aceptor do substrato ${ }^{68}$.

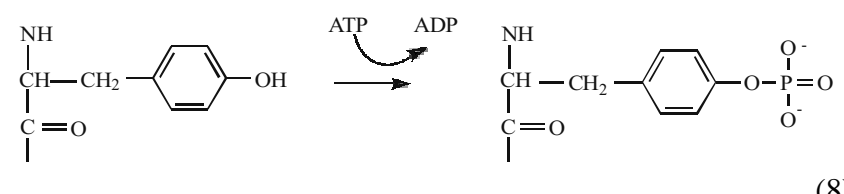

A atividade biológica do crômio está relacionada com a potencialização dos efeitos da insulina na conversão da glicose em $\mathrm{CO}_{2}$ ou em lipídeo. Os efeitos metabólicos da insulina iniciam-se com a sua ligação ao domínio extracelular do receptor da insulina junto à membrana plasmática do músculo, nas células adiposas e do fígado. A ativação subseqüente da atividade da proteína tirosina-cinase do receptor, leva à autofosforilação do receptor, assim como à fosforilação de várias outras proteínas intracelulares ${ }^{69}$.

Tendo em vista que a função da insulina constitui-se de uma sequiência de reações de fosforilação e desfosforilação, sugere-se que o oligonucleotídeo LMWCr tenha a sua participação no controle de tais reações. Tem sido demonstrado que o oligonucleotídeo LMWCr é capaz de ativar a proteína tirosina-cinase do receptor da insulina e os autores sugerem que o sítio da ativação é a unidade beta do receptor $^{70}$. A presença de íons crômio nesse oligopeptídeo é, provavelmente, o fator responsável pela atividade da fosfatase fosfotirosina, uma proteína associada às membranas ${ }^{67}$. Uma vez que o centro ativo do LMWCr contém 4 íons crômio ligados aos grupos carboxilados dos aminoácidos, a atividade de compostos multinucleares de crômio frente a estes sistemas tem sido alvo de investigações ${ }^{70}$.

Apesar de o crômio ser um nutriente essencial que pode ser encontrado em alimentos naturais, estudos revelam que a ingestão desse elemento está abaixo da quantidade diária recomendada, mesmo em pessoas saudáveis, conduzindo conseqüentemente, ao consumo de suplementos sintéticos ${ }^{71}$. Um suplemento nutricional que se tornou alvo de indústrias farmacêuticas nos EUA é o tripicolinato de $\mathrm{Cr}(\mathrm{III})$, $\mathrm{Cr}$ (pic) ${ }_{3}{ }^{72}$. No entanto, comprovou-se que este mesmo complexo é capaz de clivar a molécula do ADN, complementando outros experimentos que reportaram a capacidade do $\mathrm{Cr}(\text { pic })_{3}$ de induzir dano em cromossomos $^{73,74}$. Devido às evidências da toxidez do tripicolinato de $\mathrm{Cr}(\mathrm{III})$, tem havido um interesse renovado na obtenção de novos suplementos e entre os mais promissores estão o oligopeptídeo LMWCr e os complexos trinucleares de $\mathrm{Cr}$ (III) do tipo "básico"70, 75,76

$\mathrm{Na}$ procura de um modelo funcional para o LMWCr, foram escolhidos dois complexos trinucleares que estão estruturalmente caracterizados, são solúveis e relativamente estáveis em solução aquosa: o protótipo "básico", complexo 8, e o seu análogo contendo propionato, complexo 9, já apresentados na Figura 3. Foi demostrado que esse último tem a habilidade de ativar as proteínas tirosina-cinase e a fosfotirosina fosfatase, sendo que $\mathbf{8}$, ao contrário, é um inibidor de ambas as proteínas ${ }^{70}$. Recentemente, observou-se também que tal complexo pode provocar a desnaturação da fita dupla do ADN na presença de $\mathrm{H}_{2} \mathrm{O}_{2}$, através de um mecanismo radicalar. Os resultados mostraram ainda que 8 hidrolisa mono e diésteres fosfatos provavelmente via formação de espécies do tipo $\mathrm{Cr}(\mathrm{IV})-\mathrm{OH}^{77}$. Os mesmos investigadores observaram que, em comparação com o $\mathrm{Cr}$ (pic) , $_{3}$, o potencial do complexo 9 e do LMWCr para clivar a molécula do ADN é muito menor nas condições fisiológicas ${ }^{78}$. Embora LMWCr seja biologicamente ativo e tenha um $\mathrm{LD}_{50}$ alto, é susceptível à hidrólise em condições ácidas e, conseqüentemente, não pode ser ingerido oralmente sem degradação ${ }^{79}$. Assim sendo, supõe-se que o complexo 9 venha a ser um suplemento nutricional mais seguro para substituir o $\mathrm{Cr}(\text { pic })_{3}$. 


\section{PERSPECTIVAS}

Os avanços das técnicas espectroscópicas tem possibilitado a caracterização de complexos de $\mathrm{Cr}(\mathrm{IV})$ e $\mathrm{Cr}(\mathrm{V})$ em solução, o que proporcionou novos esclarecimentos sobre as implicações desses íons nas propriedades carcinogênicas da redução do crômio hexavalente nos sistemas fisiológicos. Os estudos com sistemas biomiméticos tem focalizado, principalmente, complexos de $\mathrm{Cr}(\mathrm{V}) / \mathrm{Cr}(\mathrm{IV})$, representantes dos intermediários reativos da reação redox do $\mathrm{Cr}(\mathrm{VI})$.

Experimentos de absorção de raios- $\mathrm{X}$ in vivo em hamster, indicaram que o crômio trivalente é o estado de oxidação predominante na redução de compostos de crômio carcinogênicos no meio celular. Os resultados dos estudos da interação do íon crômio com ADN confirmam que o sítio de coordenação preferencial são os grupos fosfatos. A fim de elucidar o modo da interação $\mathrm{Cr}(\mathrm{III})-\mathrm{ADN}$, o primeiro passo foi determinar as estruturas cristalinas de complexos contendo a ligação $\mathrm{Cr}$ (III)-diesterfosfato, que representam os primeiros modelos estruturais da interação do íon crômio com a molécula do ADN. Recentemente, estudos de EXAFS realizados com esses complexos modelos confirmaram o potencial desta técnica para investigar, no estado sólido ou em solução, os aspectos estruturais das interações $\mathrm{Cr}(\mathrm{III})$-ADN além da primeira esfera de coordenação ${ }^{80}$.

Com respeito à participação do íon $\mathrm{Cr}$ (III) no metabolismo da insulina, embora o mecanismo ainda não esteja totalmente elucidado, sabe-se que: 1) devido ao aumento da concentração de insulina no sangue, o receptor da insulina é ativado; 2) quando a insulina liga-se ao receptor, os íons de crômio passam da corrente sangüínea para as células insulina-dependentes; 3) LMWCr liga-se ao receptor da insulina, ativando posteriormente a atividade cinase (aumento da fosforilação ) do receptor. Partindo-se do fato de que complexos do tipo "básico" são ativadores em potencial das proteínas tirosinacinase e da fosfotirosina fosfatase, torna-se necessário elucidar estruturalmente a interação desses complexos trinucleares com grupos fosfatos.

A síntese e a determinação da estrutura de complexos trinucleares com ligantes atóxicos possivelmente conduzirá a novos suplementos nutricionais em potencial. Outra abordagem é a criação de sistemas biomiméticos que poderá contribuir para um melhor entendimento sobre a química do íon $\mathrm{Cr}$ (III) envolvida em sua função como elemento tóxico ou essencial.

\section{ABREVIAÇÕES}

$\mathrm{EAX}=$ espectroscopia de absorção de raios-X, RPE = ressonância paramagnética eletrônica, $\mathrm{RMN}$ = ressonância magnética nuclear, DC = dicroísmo circular, ehba = ácido 2-etil hidroxibutanoato, hmhea $=$ ácido 2,2 -bis(hidroximetil)-2-\{bis(2-hidroxietil)amino etanolato, $\mathrm{qa}=$ ácido quínico, $\mathrm{NADPH}=$ nicotinamida adenosina fosfato, pic $=$ picololinato, mal $=$ malonato, oxal $=$ oxalato, ATP $=$ adenosina trifosfato, $\mathrm{ADP}=$ adenosina difosfato, $\mathrm{ADN}=$ ácido deoxiribonucléico, phen $=1,10$-fenantrolina, salen $=$ salicildialdeído etilenodiimina, $b t=$ bis(hidroxietil)aminotris(hidroximetil)metano.

\section{AGRADECIMENTOS}

Ao CNPq, a CAPES e a FAPESP pelo apoio financeiro.

\section{REFERÊNCIAS}

1. Mertz, W.; J. Nutr. 1993, 123, 626.

2. Anderson, R. A. Em Handbook of Metal-Ligand Interactions in Biological Fluids: Bioinorganic Medicine; Berthon, G., ed.; Dekker: New York, 1995, vol. 1, p. 261-265.

3. Vincent, J. B.; Acc. Chem. Res. 2000, 33, 503.
4. Felcman, J.; Elementos Químicos Importantes para a Vida: I Cromo; Rebizzi: São Paulo, 2001.

5. Anderson, R.A.; Nutr. Rev. 1998, 56, 266.

6. IARC, IARC Monographs on the Evaluation of Carcinogenic Risk to Humans : Chromium, Nickel and Welding; International Agency for Research on Cancer: Lyon, 1990, vol .49, p. 49.

7. Buechner, W.; Industrial Inorganic Chemistry; VCH: Weinheim, 1990, p. 255.

8. Jordão, C. P.; Silva, A. C.; Pereira, J. L.; Brune, W.; Quim. Nova 1999, $22,47$.

9. Shi, X. L.; Chiu, A.; Chen, C. T.; Halliwell, B.; Castranova, V.; Vallyathan, V.; J. Toxicol. Environ. Health, Part B 1999, 2, 87.

10. Cieslak-Golonka, M.; Polyhedron 1996, 15, 3667.

11. Codd, R.; Dillon, C. T.; Levina, A.; Lay, P. A.; Coord. Chem. Rev. 2001, $216,537$.

12. Fonkeng, B. S.; Gelerinter, E.; Bose, R. N.; J. Chem. Soc., Dalton Trans. 1995, 24, 219; Codd, R.; Levina, A.; Zhang, L.; Hambley, T. W.; Lay, P. A.; Inorg. Chem. 2000, 39, 990; Headlam, H. A.; Weeks, C. L.; Turner, P.; Hambley, T. W.; Lay, P. A.; Inorg. Chem. 2001, 40, 5097.

13. Mitewa, M.; Bontchev, P. R.; Coord. Chem. Rev. 1985, 61, 241

14. Judd, R. J.; Hambley, T. W.; Lay, P. A.; J. Chem. Soc., Dalton Trans. 1989, 11, 2205.

15. Farrell, R. P.; Lay, P. A.; Comments Inorg. Chem. 1992, 13, 133.

16. Krumpolc, M.; Rocek, J.; Inorg. Chem. 1985, 24, 617.

17. Levina, A.; Lay, P. A.; Dixon, N. E.; Inorg. Chem. 2000, 39, 385

18. Bose, R. N.; Fonkeng, B. S.; Moghaddas, S.; Stroup, D.; Nucleic Acids Res. 1998, 26, 1588.

19. Codd, R.; Lay, P. A.; J. Am. Chem. Soc. 1999, 121, 7864

20. Codd, R.; Lay, P. A.; Levina, A.; Inorg. Chem. 1997, 36, 5440.

21. Bose, R. N.; Fonkeng, B; Barr-David; G.; Farrell, R. P.; Judd, R. J.; Lay, P. A.; Sangster, D. F.; J. Am. Chem. Soc. 1996, 118, 7139.

22. Larkworthy, L. F.; Nolan, K. B.; O’Brien, P. Em Comprehensive Coordination Chemistry; Wilkerson, G. F.; Gillard, R. D.; McCleverty, J. A., eds.; Pergamon Press: Oxford, 1987, vol. 3, p. 700.

23. Cannon, R. D.; Prog. Inorg. Chem. 1988, 36, 195; Eshel, M.; Bino, A.; Inorg. Chim. Acta 2001, 320, 127.

24. Nagi, M. K.; Harto, A., Donald, S.; Lee, Y. S.; Sabat, M.; O’ Connor, C. J.; Vincent, J. B.; Inorg. Chem. 1995, 34, 3813.

25. Sugden, K. D.; J. Inorg. Biochem. 1999, 77, 177.

26. Stearns, D. M.; Kennedy, L. J.; Courtney, K. D.; Giangrande, P. H.; Phiffer, L. S.; Wetterhahn, K. E.; Biochemistry 1995, 34, 910.

27. Connett, P. H.; Wetterhahn, K. E.; Struct. Bonding 1983, 54, 93.

28. Standeven, A. M.; Wetterhahn, K. E.; J. Am. Coll. Toxicol. 1990, 8, 1275.

29. Dillon, C. T.; Lay, P. A.; Bonin, A. M.; Cholewa, M.; Legge, G. J. F.; Chem. Res. Toxicol. 2000, 13, 742.

30. Kaiwar, S. P.; Raghavan, M. S. S.; Rao, C. P.; Carbohydr. Res. 1994, 256, 29.

31. Perez-Benito, J. F.; Arias, C.; Rodriguez, R. M.; Ros, M.; New J. Chem. 1998, 22, 1445 .

32. Wise, J. P.; Orenstein, J. M.; Patierno, S. R.; Carcinogenesis 1993, 14, 429

33. Standeven, A. M.; Wetterhahn, K. E.; Carcinogenesis 1992, 13, 1319.

34. Salnikow, K.; Zhitkovich, A.; Costa, M.; Carcinogenesis 1992, 13, 2341.

35. Lodish, H.; Baltomore, D.; Berk, A.; Zipursky, S. L.; Matsudaira, P.; Darnell, J.; Molecular Cell Biology; W.H. Freeman and Co.: New York, 1995.

36. Toy, A. D. F.; Walsh, E. N.; Phosphorus Chemistry in Everyday Living; American Chemical Society: Washington, 1987.

37. Bakac, A.; Wang, W. D.; Inorg. Chim. Acta. 2000, 297, 27.

38. Zhitkovich, A.; Shrager, S.; Messer, J.; Chem. Res. Toxicol. 2000, 13, 1114; Quievryn, G.; Messer, J.; Zhitkovich, A.; Biochemistry 2002, 41, 3156.

39. Yamamoto, A.; Wada, O. Em Handbook of Metal-Ligand Interactions in Biological Fluids: Bioinorganic Medicine; Berthon, G. ed.; Dekker: New York, 1995, vol. 1, p. 248.

40. Anderson, R. A. Ibid., vol. 1, p. 418.

41. Bocarsly, J. R.; Barton, J. K.; Inorg. Chem. 1992, 31, 2827.

42. Watson, R. T.; Desai, N.; Wildsmith, J.; Wheeler, J.F.; Kane-Maguire, N. A. P.; Inorg. Chem. 1999, 38, 2683.

43. Snow, E. T.; Pharmacol. Ther. 1992, 53, 31.

44. Voitkun, A.; Zhitkovich, A.; Costa, M.; Environ. Health Perspect. 1994, $102,251$.

45. Kortenkamp, A.; Ozolins, Z.; Beyersmann, D.; O’Brien, P.; Mutat. Res. 1989, 216, 19; Casadevall, M.; Fresco, P. D.; Kortenkamp, A.; Chem.-Biol. Interact. 1999, 123, 117.

46. Kortenkamp, A.; Oetken, G.; Beyersmann, D.; Mutat. Res. 1990, 232, 155.

47. Bose, R. N. Moghaddas, S.; Mazzer, P. A.; Dudones, L. P.; Joudah, L.; Stroup, D.; Nucleic Acids Res. 1999, 27, 2219.

48. Tsou, T. -C.; Yang, J. -L.; Chem.-Biol. Interact. 1996, 102, 133.

49. Farrell, R. P.; Judd, R. J.; Lay, P. A.; Dixon, N. E.; Baker, R. S. U.; Bonim, A. M.; Chem. Res. Toxicol. 1989, 2, 227. 
50. Sugden, K. D.; Wetterhahn, K. E.; Inorg. Chem. 1996, 35, 3727.

51. Levina, A.; Barr-David, G.; Codd, R.; Lay, P. A.; Dixon, N. E.; Hammershoi, A.; Hendry, P.; Chem. Res. Toxicol. 1999, 12, 371.

52. Dillon, C. T.; Lay, P. A.; Cholewa, M.; Legge, G. J. F.; Bonin, A. M.; Collins, T. J.; Kostka, K., L.; Shea-MacCarthy, G.; Chem. Res. Toxicol. 1997, 10, 533.

53. Snow, E. T.; Environ. Health. Perspect. 1994, 102, 41.

54. Sudgen, K. D.; Burris, R. B.; Rogers, S. J.; Mutat. Res. 1990, 244, 239

55. Bridgewater, L. C.; Manning, F. C. R.; Woo, E. S.; Patierno, S. E.; Mol. Carcinog. 1994, 9, 122.

56. Tasapakos, M. J.; Wetterhan, K. E.; Chem.-Biol. Interact. 1983, 46, 265.

57. Zhitkovich, A.; Voitkun, V.; Costa, M.; Biochemistry 1996, 35, 7275.

58. Nalewajski, R. F.; Struct. Bonding 1993, 80, 115.

59. Pearson, R. G.; Coord. Chem. Rev. 1990, 100, 403.

60. Ferreira, A. D. Q.; Bino, A.; Gibson, D.; Inorg. Chem. 1998, 37, 6560.

61. Ferreira, A. D. Q.; PhD Thesis; The Hebrew University of Jerusalem, Israel, 1998.

62. Balamurugan, K.; Vasant, C.; Rajaram, R.; Ramasami, T.; BBA-Gen. Subjects.1999, 1427, 357.

63. Davis, C. M.; Vincent, J. B.; Arch. Biochem. Biophys. 1997, 399, 355.

64. Yamamoto, A.; Wada, O.; Ono, T.; Eur. J. Biochem. 1987, 165, 627.

65. Vincent J. B.; J. Am. Coll. Nutr. 1999, 18, 6.

66. Davis, C. M.; Vincent, J. B.; Biochemistry 1997, 36, 4382.

67. Davis, C. M.; Sumrall, K. H.; Vincent, J. B.; Biochemistry 1996, 35, 12963.
68. Voet, D.; Voet, J.G.; Biochemistry; John Wiley \& Sons; New York, 1995 69. White, M. F.; Kahn, C. R.; J. Biol. Chem. 1994, $269,1$.

70. Davis, C. M.; Royer, A. C.; Vincent, J. B.; Inorg. Chem. 1997, 36, 5316.

71. Commitee on Animal Nutrition, Board of Agriculture, National Research Council; The Role of Chromium in Animal Nutrition; National Academy Press: Washington, 1997.

72. Anderson, R. A.; Cheng, N.; Bryden, N. A.; Polansky, M. M.; Cheng, N.; Chi, J.; Feng, J.; Diabetes 1997, 46, 1786.

73. Speetjens, J. K.; Collins, R. A.; Vincent, J. B.; Woski, S. A.; Chem. Res. Toxicol. 1999, 12, 483.

74. Stearns, D. M.; Wise, J. P.; Sr.; Patierno, S. R.; Wetterhahn, K. E.; FASEB J. 1995, 9, 1650.

75. Sun, Y. J.; Mallya, K.; Ramirez, J.; Vincent, J. B.; J. Biol. Inorg. Chem. 1999, 4, 838.

76. Lieberman, R. L.; Bino, A.; Mirsky, N.; Summers, D. A.; Thompson, R. C.; Inorg. Chim. Acta 2000, 297,1.

77. Parand, A.; Royer, A. C.; Cantrell, T. C.; Weitzel, M.; Memon, N.; Vincent J. B.; Crowder, M. W.; Inorg. Chim. Acta 1998, 268, 211.

78. Speetjans, J. K.; Parand, A.; Crowder, M. W.; Vincent, J. B.; Woski, S. A.; Polyhedron 1999, 18, 2617.

79. Sumrall, K. H.; Vincent, J.B.; Polyhedron. 1997, 16, 4171.

80. Ferreira, A. D. Q.; Zukerman-Schpector, J.; Alves, M. C. M.; XI Reunião Anual de Usuários do Laboratório Nacional de Luz Síncrotron, Campinas, Brasil, 2001. 